\title{
9 THE PHENOMENOLOGY OF INFORMATION SYSTEMS EVALUATION: OVERCOMING THE SUBJECT/OBJECT DUALISM
}

\author{
Lucas D. Introna \\ Centre for the Study of Technology and Organization \\ Lancaster University Management School \\ Lancaster \\ United Kingdom \\ Louise Whittaker \\ Graduate School of Business Administration \\ University of the Witwatersrand \\ Johannesburg \\ South Africa
}

\begin{abstract}
In this paper, we argue that the path to better IS evaluation in organizations is to get beyond the dualisms of subject/object, mind/body, and cognition/action that limit our analysis, understanding, and practice of evaluation in the flow of organizational life. We present a discussion of the unity of cognition and action using the work of phenomenologists such as Heidegger, Merleau-Ponty, and Henry. We argue that the subject/object dualism as described in the evaluation literature only seems to exist because we accept and depend on another dualism, namely the assumed split between cognition and action. We propose that managers do not apply methods, propose alternatives, argue costs and benefits, and attempt to subvert these, in order to judge or decide. Rather the applying, proposing, arguing and subverting - the discourse - is exactly already the judging and the deciding. We proceed to present a set of principles that take the unity of cognition and action seriously. We believe these point to a way of making IS evaluation more skillful while taking into account both the rational and the

The original version of this chapter was revised: The copyright line was incorrect. This has been corrected. The Erratum to this chapter is available at DOI: 10.1007/978-0-387-35634-1_28


political dimensions that now seem to stand as irreconcilable opposites.

Keywords: IS evaluation, cognition, phenomenology, dualisms

\section{INTRODUCTION}

It could be argued that information systems evaluation is among the most contentious of organizational discourses on information technology. By evaluation, we mean the process of assessing - or justifying - the value of information systems, for the purposes of organizational decision-making through some form of organizational discourse (Smithson and Hirschheim 1998). Evaluation is an ongoing managerial concern and is also generally depicted as problematic in the information systems literature. Here there is an ongoing debate between the rational functionalists (concerned with the objective application of reason and method) and the interpretivists (concerned with context, politics, culture, and the like). Organizational evaluation practice, and the presentation of that practice through research, also continues to be problematic, as managers do not seem to apply the prescribed methods, and very often do not seem to do any evaluation at all. As Smithson and Hirschheim put it, there is a considerable gap between theory and practice.

In this paper, we will argue that this perceived gap is symptomatic of a deeper, implicitly assumed set of dualisms: the dualism of subject and object as well as the related dualisms of mind and body, thought and action. Both functionalist and interpretive discussion of IS evaluation presume, to a lesser or greater degree, that evaluations (judgements about the worth of the system) are somehow reflexive moments or events - with some definitive activities and outcomes - that are more or less separate from the ongoing activity and sensemaking in the flow of everyday organizational life. The central problem for those who research, and do evaluation, thus becomes one of how best to construct or locate these moments and to determine what the procedures and methods that govern them should be.

In pointing toward the cognition/action dualism in particular, we are aware that we raise a very complex philosophical problem, which has proved to be immensely difficult for all of the major traditions over the centuries. We do not want to suggest that we have a definitive answer to the problem as such; rather, it is our aim to show that challenging certain underlying ontological assumptions about cognition and action may bring us to a new way of understanding a problem that has become rather stagnant in the way it is addressed and presented, both intellectually and in practice. 
This paper is, therefore, structured as follows: First, we shall address the IS evaluation literature, by way of describing the alternative accounts and approaches to be found in objective and subjective evaluation perspectives. These perspectives provide two archetypes of evaluation, each of which presents difficulties in theory and in practice. Second, we shall discuss why it is that these archetypes are unsatisfactory, by explicating a phenomenology of cognition and action. Finally, this phenomenology creates the context for our account of IS evaluation as an ongoing skillful conversation.

\section{INFORMATION SYSTEMS EVALUATION}

A very useful review of the information systems evaluation literature is provided by Hirschheim and Smithson (1988) and in a later, follow-up article by Smithson and Hirschheim (1998). In this analysis and critique, they classify the IS evaluation literature within three taxonomic zones, distributed along a continuum from the highly rational/objective to subjective/political, as shown in Figure 1.

At the highly rational/objective end of the continuum, Smithson and Hirschheim detail IS evaluation literature that is broadly focused on the performance and reliability of computer systems as such, located in the efficiency zone. However, they argue, information systems are required to be effective as well. It is in the shift to this zone that IS evaluation seems to become problematic. Very often, criteria of effectiveness are difficult to measure or even to define, and frequently those aspects that are measured are those that are measurable. Financial estimations of system benefit, seen as the most rational criterion for IS investment decision making, are most often the objective of techniques found in this zone (such as cost/benefit analysis, expanded cost/benefit analysis, infor-

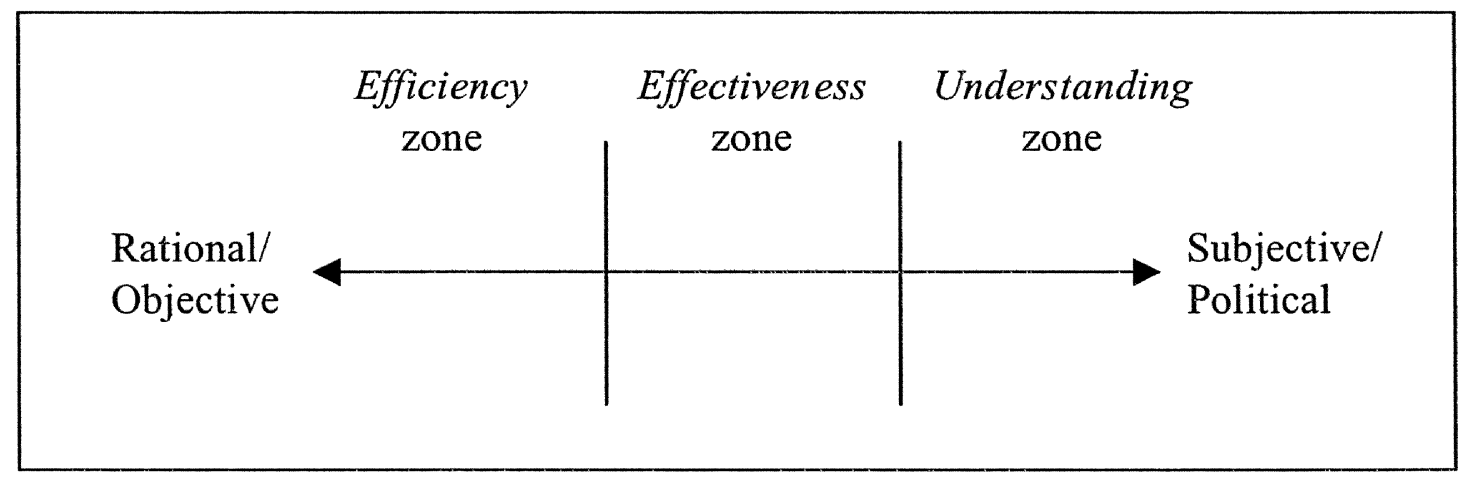

Figure 1. The Object/Subject Dualism in IS Evaluation (Hirschheim and Smithson 1988) 
mation economics, etc.). In practice however, these apparently rational techniques are often neglected in favor of more heuristic decision-making processes (Ballantine et al. 1996; Farbey, Land, and Targett 1993; Farbey, Targett, and Land 1995; Lederer and Prasad 1993). As Farbey and his colleagues point out, "many substantial investments [are] defended as 'acts of faith' or 'got to do' or simply 'strategic"' (Farbey, Land, and Targett 1999, p. 208).

Another set of techniques that seek to address the effectiveness of the system are the context-sensitive contingency techniques. Given that different types of system are seen to provide different benefits, a contingency approach may be used to provide different measures of value, depending on the purpose of the system (Farbey, Land, and Targett 1993, 1994, 1999; Farbey, Targett, and Land 1995; Hawgood and Land 1988; Hochstrasser 1990; McFarlan 1981; Silk 1990; Ward 1990). Paradoxically, although these techniques carry considerable organisational and scientific legitimacy (Walsham 1993), they do not seem to affect the actual outcome of the evaluation process. Franz and Robey (1984) suggest that where they are used, "the rational elements are tools used by participants to gain new ground or protect ground already won."

This may suggest that even where highly rational and ostensibly objective techniques are used, managers are inevitably acting in a subjective/political manner, and therefore moving toward the subjective/political end of the continuum. While, overtly, the evaluation process will involve the provision and use of information for decision making, covertly, the evaluation will have controlling and symbolic functions, which may not be admitted publicly (Langley 1989). It seems that the most important symbolic purpose of formal evaluation is as an expression of rationality. Thus, evaluation often becomes a ritual in which both the appearance of and belief in rationality are expressed (Symons and Walsham 1988)-primarily for political and persuasive effects (Farbey, Land, and Targett 1999)-rather than a substantive process through which benefits can be improved (Kumar 1990). Rituals, however, can sustain context only if they are not actually perceived as ritual, and thus fairly circumscribed, rational approaches are accorded considerable legitimacy. (Otherwise they would be perceived as just ritual and paradoxically carry no value as ritual, in a world where objective rationality is both required and valued.) It may be exactly this legitimacy that has led IS academics and consultants to formulate further frameworks and methodologies to facilitate evaluation, thereby shifting practice back toward the objective side of the continuum. Bjørn-Andersen (1988) describes this process as follows: "We tend to spend more and more time and use even more refined technological tools for solving the wrong problem more precisely."

In attempt to address the right problem other approaches can be included in the understanding zone that can be seen to be essentially interpretive, at least in their epistemology, or view of how evaluation as understanding might function. 
The several approaches that employ a context/content/process (Pettigrew 1985) framework (for example Serafeimidis 1996; Serafeimidis and Smithson 2000; Symons 1991; Walsham 1993) form part of a growing body of interpretive work in IS evaluation that has emerged over the last 10 years or so. However, although Symons (1991) in particular claims that this approach has implications for the practice of IS evaluation, it has been suggested that it is not implementable, and "remains an analysis framework" (Canevet 1996, p. 65). Most of the interpretive work on IS evaluation is interpretive in its evaluation of empirical studies, but more limited when it comes to describing IS evaluation as interpretation. As Smithson and Hirschheim point out, "within this understanding zone, there seems to be a significant gap between theory and practice" (1998, p. 171).

Thus it seems as if managers in practice are mostly presented with two opposing archetypes in evaluation. Each one operates at different ends of the Hirschheim and Smithson continuum, the objective/rational manager or the political/subjective manager. In the first, managers are exhorted to be rational and to be more disciplined in defining the object of evaluation, and in applying more rigorous methods. In the second, managers are acknowledged to be subjective (and by implication nonrational and political) in the process of evaluating an information system-although they ought not be. The theory/practice tensions of the dualism are shown in Table 1, where we summarise the apparent contradictions between theory and practice in each of the subjective and objective archetypes. There is also a tension between practice in the objective archetype, where political action is covert, and theory in the subjective archetype, where political action is, or ought to be, overt even while it aims to be fair. This contradiction, which underlines the ritualistic nature of political action (which, as discussed above must be covert to be effective), may very well account for the lack of legitimacy accorded the subjective approaches.

Table 1. The Outcome of the Dualistic View of IS Evaluation

\begin{tabular}{|l|l|l|}
\hline & \multicolumn{1}{|c|}{ Theory } & \multicolumn{1}{c|}{ Practice } \\
\hline Objective archetype & $\begin{array}{l}\text { Rational methods that are } \\
\text { reasonable and neutral } \\
\text { and therefore the only } \\
\text { legitimate option }\end{array}$ & $\begin{array}{l}\text { Becomes entangled and then } \\
\text { used ritually for political } \\
\text { reasons and to gain } \\
\text { legitimacy }\end{array}$ \\
\hline Subjective archetype & $\begin{array}{l}\text { Accepts the contextual and } \\
\text { the political but argues it } \\
\text { ought to be as neutral/fair } \\
\text { as possible }\end{array}$ & $\begin{array}{l}\text { Lacks legitimacy and is } \\
\text { therefore not explicitly } \\
\text { adopted as the preferred } \\
\text { approach }\end{array}$ \\
\hline
\end{tabular}


The important point here is that the IS evaluation discourse (discourse not actual practice), both managerial and academic, is most often characterized by these subject/object, and related, dualisms, yet it is the implicit acceptance of these very dualisms that creates the so-called tensions between theory and practice. It is our argument that the subject/object dualism as presented by Hirschheim and Smithson, and generally accepted in the evaluation literature, can only be sustained as a reasonable way of talking about the evaluation problem because it draws and depends on another dualism, namely the assumed split between cognition and action. Thus, an account of evaluation that does not draw on such a dualism will enable us both to resolve the so-called theory/ practice tension, and enable us to improve what managers actually do by not confronting them (or they themselves) with the either objective and rational or subjective and political logic. This is the aim of the sections to follow.

\section{TOWARD A PHENOMENOLOGY OF EVALUATION ${ }^{1}$}

\section{We are thinking. (Martin Heidegger)}

Evaluation - cognition or thinking -is not something that happens in the head or the mind of the manager. Processes such as the formation of ideas, the interpretation of data, and the making of decisions (often described as thought) are not linear sequences. The relation between cognition and action is not the relation between thought in the mind and behavior as a stream of discernible action in the world. Action, ${ }^{2}$ or decision making, does not presume prior thought in the way that motion presumes the existence of some prior force. Yet, we do tend to speak in this manner. We often say, "I thought it was the right thing to do," or "After considerable thought, I decided to do it." This way of speaking

${ }^{1}$ Our account aims to weave together ideas informed by the works of Heidegger (1962), Merleau-Ponty (1962), Henry (1975), and to a lesser extent Bergson (1911) and James (1996). We are aware that there are many possible responses to the problem of the unity of cognition and action as an instance, of course, of the more general problem of body and mind. There is also extensive work being done on the general problem of consciousness of which our discussion may form a small part. We want to acknowledge these wide and complex fields of research without directly engaging them as this will detract from our more modest aim. We also want to acknowledge Bogdan Costea's contribution to some of the ideas in this section.

${ }^{2}$ In our discussion we will use the term action to refer to bodily movement as well as speech. All action has as its location the body in its ongoing comportment in the world. All action consists of embodied movements simultaneously toward and in the world. 
has lead us to believe that thought is some independent event separate from, and mostly prior to, action. We tend to attribute to "I" the attribute of thinking as a result of the constraints that the subject, object, attribute structure of language imposes on us. Thus, in an attempt to give an account of ourselves, thought becomes an artefact produced in the account by the structure of language, our way of speaking. We accordingly proceed through elaborate descriptions and analysis to instantiate thought as some attribute that the "I" sometimes has and sometimes not. In Will to Power, Nietzsche (1967) warns against this habitual switch or "double error":

If I say "lightning flashes," I have posited the flash once as an activity and a second time as a subject, and thus added to the event a being that is not one with the event but is rather fixed, is, and does not "become."-To regard an event as an "effecting," and this as being, that is the double error, of interpretation, of which we are guilty (p. 289).

Here, Nietzsche draws attention to some of the foundational categorical aspects of our understanding of elementary experience. Lightning does not sometimes flash and sometimes not-the flash is the lightning. Likewise we do not sometimes think and sometimes not-we are thinking and nothing besides. When we say we are thinking (i.e., never separate from it), we are saying that thinking is an ongoing (without a specific start and a specific end) embodied (something we do) and situated (already in the flow of everyday life) concern we have with the world - we are never not concerned with world. This concern is both embodied and situated, which is what we now want to explore. In the discussion to follow, we will refer to this already concerned, situated, always thinking body as the lived-body.

Thinking/doing is, at an elementary level, profoundly personal, simultaneously at one with the person's whole concern and involvement in their world. As such, it is thus linked to the embodied, historical, and temporal unfolding of ongoing human existence. To say this is not to say that the manager is an enclosed subject, absorbed and lost in his/her own consciousness. Thought is exactly that which emerges because we are always already concerned or directed toward the world. As such the world often resists our concern and directedness, thereby forcing us to reorient ourselves (or in cognitive language to reconsider our thoughts). In a way, we could say thought is the relational comportment between the body and the world; in short, it is our situated beingin-the-worldness (Heidegger 1962). Thinking is what we already do when we orient ourselves in our talking, walking, touching, feeling, and listening, as our ongoing concern in the flow of everyday life. Cognition is action and action is 
cognition. Alternatively stated: the mind is the lived-body and the lived-body is the situated mind.

To help us understand this, we can consider an example of a manager who must evaluate a customer management information system, by considering (and coming to some judgement about) that system, to make or motivate a rational decision. This thinking, evaluating manager is an already situated manager inthe-world (Heidegger 1962). She is not a Cartesian subject holding objective or subjective views about the system, but a being-in-the-world, a manager-in-theorganization. The world is not "simply out there," but is something in which the manager is always already situated - already involved, already committed, and already compromised. The manager is not an autonomous, self-sufficient source of intelligibility possessing mental states and acting in terms of an essentially disinterested intentionality. Rather, she derives her being (her intelligibility) from always already being-there (busy and engaged in-the-world). Thus, as a manager-in-the-organization, she is always already involved (directed, concerned) with the world (practices and systems) in the way managers are. We shall refer to her as an always already involved manager or simply an involved manager (Introna 1997).

The involved manager understands-always already has a sense of - what she does or needs to do. As such, possibilities for action (potential decisions about the system) show up or stand out as relevant without her explicitly considering them. She understands the system within the context of her organization and the customers it serves without having to consider or think about it as a separate object in itself that now confronts her. It is similar to other things understood through the skills and practices that she embodies. (For example, she does not have to consider explicitly the pen in order to draw on its possibilities for writing; she simply uses it as part of the ongoing practice of writing.) Obviously, the information system appears, or rather is available, as a more complex landscape of possibilities that she may get wrong. However, this getting it wrong is exactly part of her situated involvement and engagement with the world. Equally, it is often impossible for her to make this situated understanding completely explicit because, for the most part, she has no beliefs, principles, or rules (in the cognitivist sense) but only situated skills and practices. Thus, the manager does not evaluate the customer management information system (i.e., consider its possibilities for being) as something somehow strange that she now must make her mind up about or, in cognitivist language, make a decision about. As an involved manager, these situated skills and practices are appropriate concerns based on the horizon of possibilities spread around her-what Merleau Ponty calls the intentional arc: 
Let us therefore say rather, borrowing a term from other works, that the life of consciousness-cognitive life, the life of desire or perceptual life-is subtended by an "intentional arc" which projects around about us our past, our future, our human setting, our physical, ideological and moral situation, or rather which results in our being situated in all these respects. It is this intentional arc which brings about the unity of the senses, of intelligence, of sensibility and motility (1962, pp. 135-136).

The manager does not need to visualize these possibilities and her own intentions separately in order to act purposefully. These possibilities already suggest the very intentionalities that she draws upon and accomplishes as she goes about being an involved manager. As a simple example: in leaving her office to go to a meeting in another building, she does not need to make a decision to exit her office; she does not need to visualize the door, the handle, and the movements required to open it; she does not need to determine the shortest route to the door; and, finally, she does not need to coordinate them into a coherent set of thoughts and actions in order to leave the office on her way to the meeting. Leaving the room is the obvious next step in order to go to the meeting. The layout of the room already suggests the route to the door, the door already suggests the possibility for leaving, the door handle, the possibility for opening it. Her hands remember the movements of opening doors. Thus, she simply gets up and walks out to the meeting. Put another way, the world is, as Henry (1975) argues, for the lived-body an always already fully immanent horizon of possibilities. Every next move is the obvious next step already suggested in the meaningful referential whole of going to a meeting in another building. Likewise, the manager does not withdraw from the world to think before engaging in a discussion about the value (or not) of the proposed system. The flow of the discussion is the flow of the argument. She thinks her argument as she speaks, and is often surprised by her thoughts as she speaks. Thus, in the context of the discussion, her involvement, that which was already said, the direction of her speaking, the requirements of coherence and continuity, her competence at articulation, the expressions on the faces of her fellow managers, etc., all already suggest the horizon of possibilities for the next sentence, so she simply speaks (as she simply walks). She steps through the argument in a similar way she moves from one building to another.

Thus, we find that the experienced or involved manager often protests that she does not need methods and techniques to decide what to do; she argues that she knows intuitively what the right systems are because, for her, this world is familiar and obvious. She may find methods and techniques useful as a way of expressing what she already feels; however, they do not help her to decide. 
Thus she often defends the need for investments in systems as have to do or simply strategically important. The manager-in-the-organization decisions, as possibilities for action, will emerge through ongoing engagement and be taken rather than be made as such. Thus, whenever the manager needs to resolve a situation through evaluation, she may see a particular judgement as an entirely obvious next step to be taken, or she may find herself in a situation of relative unfamiliarity, the way she may when she gets off an airplane in a different country. Although there is a plenty that is unfamiliar, there is a lot that already shows up as relevant possibilities from her world of traveling. Thrown into the situation, her decisions will flow from the fact that she is already familiar with traveling and airports. As such, some possibilities will already show up and others not at all. As she engages the situation (signs, buildings, other travelers, officials, etc.), certain possibilities become progressively excluded until she finds herself committed to a particular course of action, a course of action that emerges as available and makes sense within the world she is already in. Rather than making a decision, she proceeds from irresolution/unfamiliarity to resolution/familiarity. If she were interrupted, at some point, and asked when and why she made a decision to follow a particular course of action she would find it difficult to give an account of the decisions. One may object at this point and argue that it is a reasonable account for those activities that are simple and routine but is not adequate for complex non-routine judgements. However, experienced stockbrokers, pilots, football players, and chess masters will most likely agree that in extremely complex situations this is exactly what they do-as also confirmed in the work of Damasio (1994) and Dreyfus (1993). In fact, we would argue that it is often the availability of time for extensive discussion of problems and alternative solutions in organizations that creates the impression that we have thought about them carefully.

Thus, while the manager may give an account of herself as thinking about and then structuring a decision about the system, her condition of being in the world as a lived-body does not allow for such a separation. It does, however, allow for the ongoing meandering between irresolution and resolution. Resolution and action - applying methods, proposing, arguing as part of the evaluation conversation-are not the realization of preexisting thought but the very accomplishment of it as Merleau-Ponty argues:

what misleads us into this connection, and causes us to believe in a thought which exists for itself prior to expression [action], is thought already constituted and expressed [as prior speech and action], which we can silently recall to ourselves, and through which we acquire the illusions of an inner life [mind] (1962, p. 183). 
Thus when the involved manager plans (resolves) to do something, she already has available possibilities for action (or speech). They are already there in her situated and socialized lived-body. The lived-body is the mind in the world. The manager, the subject, is never removed from her body and her body is never removed from the world.

If this is true, what about all the activities that managers refer to when they do evaluation such as reflection, consideration, judgement, and decision making? Are they not thinking, is this not cognition? In these activities of thought do they not recall something or imagine future possibilities? Here it is important to realize that when the manager recalls or imagines a possibility for action, she does not recall some image of action numerically distinct from action itself. She imagines and recalls it in the world, and her powers of imagining are nothing but the persistence of her world, as her horizon of possibilities, around her, even if it is visualized in the minds eye. To recall something, even when we experience that we forget something and then remember it, is not a recalling of some image but rather an active involvement. For example: if my lived-body forgets how to use a tool I do not sit passively and try to recall from some past an image or picture of me using it. On the contrary, I tend to pick it up and fiddle with it. In fiddling with it my lived-body remembers or rather becomes attuned to it again. Yet, the fiddling is not some random collection of actions. The previous using of the tool is present as the transcendental ${ }^{3}$ possibilities for making the fiddling meaningful and thereby allowing the possibility of meaningful use to emerge again. Thus, what we call thinking is often a shift of attention or the fiddling with things or words to allow what is present as the past to emerge into the focal awareness of getting on with the task at hand. Thus, in the evaluation conversation the applying of methods, the proposing of alternatives, the arguing of costs and benefits (and the attempt to subvert these) often function as ways of fiddling about so as to recall what we already know as active, involved, and situated managers.

The sceptics may argue that the phenomenologists (Heidegger, MerleauPonty) cannot directly demonstrate that thinking is our historical, embodied, and situated activity in the world of everyday life, and they may be right. If thinking is indeed our historical, embodied, and situated activity in the world then we can not see it as such since any "attempt of introspective analysis [of thought] is in fact like seizing a spinning top to catch its motion, or like trying to turn up the gas quickly to see how darkness looks" (James 1996, p. 117). We cannot think thinking in the way that we can not see seeing or touch touching since we can not gain a third person perspective on that which we ourselves are. In

${ }^{3}$ With transcendental, we mean that which constitutes and thereby renders the empirical possible. 
thinking - here understood as situated doing and talking - we are never removed from our ongoing embodied openness to the world. As Henry argues,

all intentionalities in general, and consequently, the essential intentionalities of consciousness are known originally in the immanence of their very being and in their immediate accomplishment (1975, p. 16, emphasis added).

To insist on a third person account of thinking is like insisting on an account of seeing. Of course, we can give an account of the biology of the visualization system. However, we cannot give an account of seeing because we cannot see our seeing as such. We cannot draw its boundaries or decipher its logic. To draw boundaries and attribute logic is to exclude the very phenomenon we are attempting to circumscribe. We cannot say where or why thinking happens accept to say it is always already there when speech and action happens. They interpenetrate each other in an irreducible manner. Is it in the body, in the world, or in the ongoing situated relation between the body and the world? The distinctions of conscious, subconscious, and preconscious are all rather arbitrary - and possibly of very little use in understanding the unfolding presence of thought/action. Likewise, the distinction body/world is probably quite arbitrary. What is a body without a world - or a world without a body? They are each other's possibilities for being.

What are the implications of accepting this phenomenological account of cognition and action for IS evaluation? This will be the question we will attempt to answer in the next section.

\section{EVALUATION AS AN ONGOING SKILLFUL CONVERSATION}

All of our discussion thus far must, if it is to be useful, somehow enable managers to begin to reconcile what they believe they ought to do with what they consistently tell us they actually do. Whereas managers would like to engage in neutral, rational (or at least reasonable) evaluation and decisions about information systems, they also find that the process is inherently political in practice. An understanding of evaluation in-the-world can point us toward a reasonable basis for evaluation. Speaking, thinking, decision making (as described in the previous section) is a unity that we would propose to capture in the notion of a conversation. We propose the notion of conversation as it includes the essential elements of situated directedness and ongoing dialectical movement (to and fro) as an exemplar of the unity of cognition and action. Thus we argue that evaluation can best be viewed as an ongoing conversation 
(thinking and doing) which is itself part of the larger conversation that is the organization. Such a view can be supported by the now widely accepted work on the narrative basis of cognition (Boland and Schultze 1996; Bruner 1990).

We take it for granted that the organizational imperative ${ }^{4}$ requires from managers that they try to make the evaluation conversation skillful rather than merely ritualistic or political. Note we use merely here as it is clear that it will never not be political, since it is already in-the-world, and the world (organization) is precisely constituted and reconstituted through power asymmetries that it depends on for its ongoing functioning (Foucault 1984). We therefore implicitly agree with Foucault that everything is already political — rather than equal and neutral - since we have argued above that it is exactly the always already interested engagement of the manager that is the necessary condition for the possibility of resolution.

We cannot develop the full argument as to what can make the IS evaluation conversation skillful in this paper (refer to Whittaker 2001 for this). However, we want to propose some heuristics of such an ongoing skillful evaluation conversation. These heuristics would take into account the simultaneity of embodied situated understanding that is always already also political. As such it would address the dualistic problems outlined in the first section. These heuristics should not in any way be seen as rules or method, but rather as ways of conducting (as well as talking about) the evaluation conversation.

We would propose that the skillful evaluation conversation has two dialectical movements: a construction and a deconstruction movement. However, these dialectical movements do not necessarily produce a synthesis (as per Hegelian logic) but rather a productive tension that provides the energy and resources for the conversation to be ongoing and in principle always incomplete. This incompleteness is crucial to making sense of IS evaluation as a political process as well as an understanding process. We cannot ever escape politics or think/be outside of power, but we can act within politics and power more or less skillfully (and ethically, which is really what we ought to do), by being able not only to construct conversations, but deconstruct them as well.

\subsection{Construction}

The construction of the evaluation conversation will be more skillful if it is an improvisatory process based on embodied situated understanding. What does

${ }^{4}$ We take it for granted here that organizations, whatever their status, operate with the objective of optimal efficiency and effectiveness-whatever optimal may mean will obviously be contested from context to context but we will not pursue this further here. 
this mean? To explain this, we will explore the following heuristics: skillful engagement, narrative construction, informing the conversation, and improvisation.

Skillful engagement: Managers involved in the evaluation conversation need a skillful (embodied, lived, and situated) understanding of the situation in which they are engaged. Such understanding can never be derived from method (although it does not preclude the development of method) but from the managers' engagement with the situation, because the managers' thinking/ peaking about the system can only grapple with a world they are already in. The simple implication of this principle is that the managers require not only experience of the system context but also a significant depth of engagement with the evaluation situation. A fragmented and superficial involvement will necessarily be inadequate for situated understanding or familiarity, and will most likely result in a move toward technical reason and mere political maneuvering (Introna 1997, p. 1). In other words, it is unlikely to be delegated to consultants or even executive directors unless they have a significant engagement and familiarity with the disclosive space in question. This has significant implications for the simple question of who conducts the evaluation.

Narrative construction: The way in which the conversation is constructed is crucial to what may, or may not, be thought about. If we specify that "only rational methods that present a valid business case" are acceptable accounts or forms for articulation (narratives), then we will limit the possible ways of speaking/thinking about our organizations and systems, because it is in telling these stories that we think. Instead of coming to a skillful evaluation based on the pragmatic, situated, social narrative available to them, managers end up paying lip service to the importance of method, and employing frameworks and techniques in overly simplified, and often also cynical ways. This is not to say that theories and models themselves must become inadmissible, but rather that they should be open to challenge on the basis of practical wisdom (phronesis ${ }^{5}$ ). Too many managers are intimidated by theories and conceptual frameworks, to the point where they surrender their own understanding (practical wisdom) in deference to the models. For the organization, this principle suggests that a radical departure from the traditionally admissible forms of communication to other forms such as storytelling and play may be necessary.

Informing the conversation: Involved understanding "is not the same as representational knowing" (Introna 1997, p. 70). The manager's skill does not derive from knowing the facts about the organization. Information, such as cost and benefit analysis, does not provide the input or basis for decisions. Infor-

${ }^{5}$ Phronesis is the sort of practical wisdom people have as a result of embodied situated understanding (Aristotle). 
mation in the context of the evaluation conversation is useful as "equipment inorder-to get the job done" (Introna 1997, p. 180). They represent ways of fiddling to recall what is already understood. The specified costs of the system only make sense in the context of its benefits, which only make sense in the context of the organization and its strategy, style and contingent circumstances, which are understood by the involved managers because they are engaged in the historical process of collaborative, situated, and narrative knowing that is the organization. Only the possibilities already understood by the managers, through resolution, can show up. In other words, additional information is useful because it may articulate distinctions about the situation, not because it is structured data, intelligence, or power in itself. As Boland points out, "These fantasies lead us to ignore the fundamental nature of interpersonal dialogue [and resolution] in the achievement of meaning" (1987, p. 363).

The implication of this is that the quantity of information generated in the evaluation process is of far less significance than the quality, not in the sense of accuracy or truth, but in the sense that it can articulate for the managers meaning about the system that is congruent with (which is not to say that it agrees with, but that it can be understood in terms of) their practical consciousness, their historical engagement within the organization. Information about any system must be grounded in the "collective practices that give it sustained social meaning" (Spender and Grant 1996, p. 55), rather than necessarily determined by forms or frameworks that have to be filled in, or calculations that have to be completed.

Improvisation: All three of the principles discussed thus far are congruent with a notion of evaluation as situated, pragmatic, contingent: that is, in some sense, improvised. Managers improvise in the evaluation conversation all the time. Every good conversation is improvisation par excellence-as we very well know. In understanding a particular information system, managers do not "sit and think about it," as this does not make sense as explained above; they fiddle by talking about it informally and formally. To paraphrase Ciborra (1999), the challenge then becomes to base the evaluation process on the systematic appreciation and nurturing of emerging practices of improvised, serendipitous conversations. We do not simply need more sophisticated techniques, or more structured processes. We need to appreciate and trust the flexibility and appropriateness of improvisation, and "enable tout court the free exercise of intuition and ingenuity" on the part of managers (Ciborra 1999, p. 152). Instead of looking for more discipline on the part of managers, in the application of more rigorous methods, we should encourage understanding through the free play of ideas, the association of multiple stakeholders in the process. Managers should be encouraged to explore as many ramifications of the system as possible, casting the net of their conversation to include the noneconomic, the unlikely, 
and even the so called irrational. A reasonable evaluation need not be determined by only rule-governed processes and fixed decision-procedures. Rather than such technical rationality, we require reasonable reason, which is to be found in "protest, dissent and free play, the skill in writing differently and thinking differently, of debating openly" (Caputo 1987, p. 234).

Such improvisation as a means of local action would, we believe, help managers to construct conversations that are a little better, a little more meaningful in sustaining skillful conversation in the evaluation process. Still, these are only local strategies for local action. It is impossible (and probably undesirable) that the conversation will be constructed entirely differently, outside of any requirement for rational methods, or outside of any inappropriate play of politics.

There is, in addition to construction, a further imperative (with a small "i"), which is to deconstruct this construction. By this we mean that the managers must also engage with the evaluation as a text and attempt a double reading of the situation. Some heuristics for how they might begin to do this follow.

\subsection{Deconstruction}

Deconstruction does not attempt to collapse the existing scheme, leaving nothing but destruction and chaos; deconstruction is not destruction. Such aims might indeed be "dangerous, and potentially disabling" (Parker 1995). Instead, in asking managers to deconstruct the evaluation conversation, we are asking them to seek in the evaluation the different/deferred - that which has not been said or has been displaced in the already said. Deconstruction is a process of not just confessing, but surfacing the inadequacy of the account, the insufficiency of the evaluation conversation as it stands. Ultimately the aim (if it has an aim) of deconstruction is to destabilize the certainty of every conclusion by impregnating it with the conviction that we may have it wrong, that it could have been otherwise. This deconstruction proceeds through a double reading of the text, a commentary and a deconstruction, in order to find the chiasmus (Critchley 1999), the point at which these cross. At this point, there might be some interlacing of meaning, some better understanding, which will, nonetheless, itself still and always be provisional. In the following sections, we will discuss each of these: commentary, deconstruction, and provisionalness.

Commentary: The evaluation conversation always proceeds within the regime of truth of rationality and efficiency. It will inevitably incorporate the technical rational perspective, and probably also those techniques that operate within this perspective - or, for that matter, any dominant regime of truth that may replace it. In deconstructing this conversation, managers must understand 
first of all the evaluation as it is from this technical rational perspective. To discount these as irrelevant and useless is foolish and counterproductive as they are already legitimate. The skilled managers must, first of all, thoroughly understand the evaluation conversation on its own terms, and interpret it in terms of its own meanings. Obviously skillful managers are aware that the formal approaches are highly deficient in generating real understanding of the costs and benefits of the system (Walsham 1993). That said, it is important that the first reading of the evaluation conversation must attempt to establish a dominant interpretation, or at least a minimal consensus, without becoming subject to a pervasive and overwhelming cynicism.

Deconstruction: Having first constructed some sort of conversation, and a commentary or interpretation of it, the next imperative is for managers to deconstruct the evaluation conversation. This is probably the most difficult idea of all, and will be the most problematic of the heuristics, simply because it is so unfamiliar, and will place the managers on such uncertain ground. After all, deconstruction, which seeks the "destabilization of the stability of the dominant interpretation" (Critchley 1999, p. 23), is to take politics seriously. The questions that must be asked in deconstruction are, therefore, the difficult ones. They relate to the voices that have not yet been heard, that which has not yet been said. They require us to acknowledge overtly the political realities of the evaluation conversation and query what or whom it is that such a reality might have excluded. Who will benefit from the current evaluation, why, or why not? Are there alternative interpretations? If deconstruction is taken seriously, with affirmation rather than cynicism, then managers, we think, will find that it is worth risking. Obviously the difficulty here is that power is most effective when it hides itself as Foucault has argued. Deconstruction as the opening up of power may encounter insurmountable obstacles. Nevertheless, this is the best we can do if we want to take politics and power seriously. It seems better to us than seeking to legitimize it through a ritualistic use of method.

Provisionalness/Undecidability: Whatever understanding is reached on the basis of the interpretation and deconstruction of the evaluation can only ever be provisional. In evaluating an information system, managers, having reached some sort of reasonable understanding, must acknowledge that what they understand may be skillful because it is situated and pragmatic, but that it is therefore also only something that seems reasonable now. It is striking, in most organizations, how few managers are prepared to backtrack, to admit that circumstances have changed, and that things did not work out quite as they might have anticipated. The requirement to save face is apparently, as Argyris (1996) suggests, universal. This is not reasonable reason. There is no reason why managers should be expected to know what cannot yet be known, to foresee the unforeseeable. And to close decisions, to resist alteration and difference, 
simply because a decision has been made cannot ever be skilled or competent behavior, whatever reasoning or rationality may have underpinned the original conclusion. If the evaluation conversation is accepted as part of the ongoing discourse of the organization, then it must itself be ongoing, as is the organization. Managers should acknowledge that inherent in every singular evaluation situation there is so much one just does not get to (and will never get to even if we have much more time and resources). This means that there is a fundamental undecidability inherent in every evaluation. Here undecidability is not the opposite of decidability but rather the opposite of calculably, programmability, formalizability and the like. It is not merely being trapped in the tension between two equally relevant possibilities, thereby being paralyzed like a deer caught in the headlights. An evaluation that did not go through the ordeal of the undecidable is not an evaluation-it is a calculation. But more than this, undecidability is never resolved, never finally passed over. It is there before, during, and after the evaluation has been made. Undecidability

remains caught, lodged, at least as a ghost - but an essential ghost-in every decision, in every event of decision. It ghostliness deconstructs from within any assurance of presence, any certitude or any supposed criteriology that would assure us of the justice of a decision, in truth of the very event of a decision (Derrida 1992, p. 25).

It seems to us that we will just be more realistic in our evaluation attempt if we take these heuristics seriously. Having said that, we want to acknowledge that it is not a matter of getting it right once and for all but rather to trying to do it better than before.

\section{CONCLUSION}

In this paper, we have argued that the path to better evaluation is not more methods or better political maneuvering but an acceptance of the interpenetration of these in knowing and doing in the flow of organizational life; to resolve to speak about evaluation in the way that we do evaluation-without recourse to dualisms. Clearly in the face of the massive investments in IT, and the consistently substantial level of failure of systems, we are indebted to our organizations and to society at large to become more skillful in what we do. Obviously, the heuristics suggested in the final part of this paper are deceptively simple, and undoubtedly fiendishly difficult in the ongoing flow of organizational practice. Yet, we believe, this is the nature of the beast and trying to 
simplify it through recourse to dualisms is to postpone perpetually our duty to face the seemingly contradictory simultaneity of reason, method, politics, and situated understanding as the very possibilities for better evaluation.

\section{REFERENCES}

Argyris, C. "Skilled Incompetence," in K. Starkey (ed.), How Organizations Learn. London: International Thomson Business Press, 1996, 82-91.

Ballantine, J. A., Galliers, R. D., and Stray, S. J. "Information Systems/Technology Evaluation Practices: Evidence from UK Organizations," Journal of Information Technology, (11), 1996, pp. 129-141.

Bergson, H. Matter and Memory, trans. by N. Paul and S. Palmer. London: George Allen \& Unwin Ltd., 1911.

Bjørn-Andersen, N. "A Post-Modernistic Essay on Technology Assessment," in N. BjørnAndersen and G. B. Davis (eds.), Information Systems Assessment: Issues and Challenges. Amsterdam: North Holland, 1988.

Boland, R. J. "The In-formation of Information Systems," in R. J. Boland Jr. and R. A. Hirschheim (eds.), Critical Issues in Information Systems Research. Chichester: John Wiley \& Sons Ltd., 1987, pp. 363-379.

Boland, R. J., and Schultze, U. "From Work to Activity: Technology and the Narrative of Progress," in W. J. Orlikowski, G. Walsham, M. R. Jones, and J. I. DeGross (eds.), Information Technology and Changes in Organizational Work. London: Chapman \& Hall, 1996, pp. 308-324.

Bruner, J. S. Acts of Meaning. Cambridge, MA: Harvard University Press, 1990.

Canevet, S. The Role of Information Systems Evaluation Across an Extended System Life Cycle. Unpublished Ph.D Thesis, London School of Economics, 1996.

Caputo, J. D. Radical Hermeneutics: Repetition, Deconstruction, and the Hermeneutic Project (Studies in Phenomenology and Existential Philosophy). Bloomington, IN: Indiana University Press, 1987.

Ciborra, C. U. "A Theory of Information Systems Based on Improvisation," in W. L. Currie and B. Galliers (eds.), Rethinking Management Information Systems. Oxford: Oxford University Press, 1999, pp. 136-155.

Critchley, S. The Ethics of Deconstruction: Derrida and Levinas ( $2^{\text {nd }}$ ed.). Edinburgh: Edinburgh University Press, 1999.

Damasio, A. R. Descartes' Error: Emotion, Reason and the Human Brain. New York: Harper Collins, 1994.

Derrida, J. "Force of the Law: The 'Mystical Foundation of Authority'," in D. Cornell, M. Rosenfeld, and D. G. Carlson (eds.), Deconstruction and the Possibility of Justice. London: Routledge, 1992.

Dreyfus, H. L. What Computers Still Can't Do: A Critique of Artificial Reason. Cambridge, MA: The MIT Press, 1993.

Farbey, B., Land, F., and Targett, D. How to Assess Your IT Investment: A Study of Methods and Practice. Oxford: Butterworth-Heinemann, 1993.

Farbey, B., Land, F., and Targett, D. "IS Evaluation: A Process for Bringing Together Benefits, Costs and Risks," in W. L. Currie and B. Galliers (eds.), Rethinking Management Information Systems. Oxford: Oxford University Press, 1999, pp. 204-228.

Farbey, B., Land, F., and Targett, D. "A Taxonomy of Information Systems Applications: The Benefits Evaluation Ladder," European Journal of Information Systems (4), 1994, pp. 41-50. 
Farbey, B., Targett, D., and Land, F. "Evaluating Business Information Systems: Reflections on an Empirical Study," Information Systems Journal (5), 1995, pp. 235-252.

Foucault, M. "Truth and Power," in P. Rabinow (ed.), The Foucault Reader: An Introduction to Foucault's Thought. London: Penguin Books, 1984, pp. 51-75.

Franz, C., and Robey, D. "An Investigation of User-Led System Design: Rational and Political Perspectives," Communications of the ACM (27:12), 1984.

Hawgood, J., and Land, F. "A Multivalent Approach to Information System Assessment," in N. Bjørn-Andersen and G. B. Davis (eds.), Information Systems Assessment: Issues and Challenges. Amsterdam: North Holland, 1988.

Heidegger, M. Being and Time, trans. by J. Macquarrie and E. Robinson. Oxford: Basil Blackwell, 1962.

Henry, M. Philosophy and Phenomenology of the Body, trans. by G. Etzkorn. The Hague: Martinus Nijhoff, 1975.

Hirschheim, R., and Smithson, S. "A Critical Analysis of Information Systems Evaluation," in N. Bjørn-Andersen and G. B. Davis, Information Systems Assessment: Issues and Challenges. Amsterdam: North Holland, 1988, pp. 17-37.

Hochstrasser, B. "Evaluating IT Investments: Matching Techniques to Projects," Journal of Information Technology (5:4), 1990, pp. 215-221.

Introna, L. Management, Information and Power: A Narrative of the Involved Manager. London: Macmillan, 1997.

James, W. A Pluralistic Universe: Hibbert Lectures at Manchester College on the Present Situation in Philosophy. Lincoln, NE: University of Nebraska Press, 1996.

Kumar, K. "Post Implementation Evaluation of Computer-Based Information Systems: Current Practices," Communications of the ACM (33:2), 1990, pp. 203-212.

Langley, A. "In Search of Rationality: The Purposes Behind the Use of Formal Analysis in Organizations," Administrative Science Quarterly (34), 1989, pp. 598-631.

Lederer, A. L., and Prasad, J. "Information Systems Software Cost Estimating: A Current Assessment," Journal of Information Technology (8), 1993, pp. 22-33.

McFarlan, F. W. "Portfolio Approach to Information Systems," Harvard Business Review, September-October, 1981, pp. 141-150.

Merleau-Ponty, M. Phenomenology of Perception, trans. by C. Smith. London: Routledge, 1962.

Nietzsche, F. W. The Will to Power, trans. by R. Hollingdale and W. Kaufmann. London: Random House, 1967.

Parker, M. "Critique in the Name of What? Postmodernism and Critical Approaches to Organization," Organization Studies (16:4), 1995, pp. 553-564.

Pettigrew, A. M. "Contextualist Research and the Study of Organizational Change Processes," E. Mumford, R. Hirschheim, G. Fitzgerald, and T. Wood-Harper (eds.), Research Methods in Information Systems. Amsterdam: North-Holland, 1985.

Serafeimidis, V. "Information Technology Investment Evaluation: Rationale, Concepts and Facilitation,"in M. Khosrowpur (ed.), Information Technology Management and Organizational Innovations. Harrisburg, PA: Idea Group Publishing, 1996, pp. 183-191.

Serafeimidis, V., and Smithson, S. "Information Systems Evaluation in Practice: A Case Study of Organizational Change," Journal of Information Technology (15), 2000, pp. 93-105.

Silk, D. J. "Managing IS Benefits for the 1990s," Journal of Information Technology (5), 1990, pp. 185-193.

Smithson, S., and Hirschheim, R. "Analyzing Information Systems Evaluation: Another Look at an Old Problem," European Journal of Information Systems (7), 1998, pp. 158-174.

Spender, J.-C., and Grant, R. M. "Making Knowledge the Basis of a Dynamic Theory of the Firm," Strategic Management Journal (17), Number Winter Special Issue, 1996, pp. 45-62.

Symons, V. J. "A Review of Information Systems Evaluation: Content, Context and Process," European Journal of Information Systems (1:3), 1991, pp. 205-212. 
Symons, V., and Walsham, G. "The Evaluation of Information Systems: A Critique," Journal of Applied Systems Analysis (15), 1988, pp. 119-132.

Walsham, G. Interpreting Information Systems in Organizations. New York: John Wiley \& Sons, 1993.

Ward, J. M. "A Portfolio Approach to Evaluating Information Systems Investments and Setting Priorities," Journal of Information Technology (5), 1990, pp. 22-231.

Whittaker, L. Information Systems Evaluation: A Post-Dualist Interpretation. Unpublished Ph.D. Thesis, University of Pretoria, 2001.

\section{About the Authors}

Lucas D. Introna is a Reader in Organization, Technology and Ethics in the Centre for the Study of Technology and Organization at Lancaster University. His research interest is the social dimensions of information technology and its consequences for society. In particular, he is concerned with the way information technology transforms and mediates social interaction with specific reference to the moral dimension. He was associate editor of Information Technology \& People (1996-2000) and is coeditor of Ethics and Information Technology. He is a founding member of the International Society for Ethics and Information Technology (INSEIT) and an active member of IFIP WG 8.2, the Society for Philosophy in Contemporary World (SPCW), and a number of other academic and professional societies. His most recent work includes a book, Management, Information and Power, published by Macmillan, and various academic papers in leading journals and conference proceedings on a variety of topics such as theories of information, privacy, surveillance, information technology and postmodern ethics, autopoiesis and social systems, and virtual organizations. He holds degrees in Management, Information Systems, and Philosophy. Lucas can be reached by e-mail at 1.introna@lancaster.ac.uk.

Louise Whittaker is a senior lecturer in Information Management at the Graduate School of Business Administration, University of the Witwatersrand in Johannesburg. Her research interests include the organizational effects of information technology, the evaluation of information systems, and information systems and organizational strategy. She is particularly interested in a phenomenological approach to understanding these issues. She completed her Bcom and MCom degrees at Wits. Her Ph.D. thesis, entitled Information Systems Evaluation: A Post-Dualist Interpretation, was completed at the University of Pretoria. Louise is a member of IFIP WG 8.2. She can be reached by e-mail at whittaker.1@wbs.wits.ac.za. 